\title{
Prevalence of medication-related incidents in an intensive care unit
}

\author{
Prevalência de incidentes relacionados à medicação \\ em unidade de terapia intensiva
}

Francino Machado de Azevedo Filho'

Diana Lúcia Moura Pinho ${ }^{1}$

Ana Lúcia Queiroz Bezerra²

Robson Tostes Amaral ${ }^{3}$

Keywords

Medication errors; Patient safety; Nursing service hospital; Nursing assessment; Intensive care units

Descritores

Erros de medicação; Segurança do paciente; Serviço hospitalar de enfermagem; Avaliação em enfermagem; Unidades de terapia intensiva

Submitted February 17, 2015 Accepted March 31, 2015

\section{Corresponding author}

Francino Machado de Azevedo Filho Campus Universitário Darcy Ribeiro, Brasília, G0, Brasil.

Zip Code: 70910-900

francin021@gmail.com

\section{DOI}

http://dx.doi.org/10.1590/1982-

0194201500056

\begin{abstract}
Objective: To estimate the prevalence of medication-related incidents in an intensive care unit.

Methods: Cross-sectional study that included 116 records of hospitalizations within a 12-month period. The survey instrument was developed based on the study variables and was validated by two experts. The prevalence was calculated by considering the number of exposed hospitalizations as the numerator and the total of investigated hospitalizations as the denominator, calculating a 95\% confidence interval. Fisher's exact test assuming maximum significance level of $5 \%(p<0.05)$ was used to verify significant association.

Results: It was observed that 113 hospitalizations had been exposed to at least one type of incident, totaling 2,869 occurrences: 1,437 reportable circumstances, 1,418 no-harm incidents, 9 near-miss incidents and 5 adverse events. The incidents occurred during the prescription stage (45.4\%) and the absence of information on the actions taken by the health professionals in relation to the incidents was identified in $99 \%$ of the records. Conclusion: Prevalence of $97.4 \%$ of medication-related incidents was estimated.
\end{abstract}

\section{Resumo}

Objetivo: Estimar a prevalência de incidentes relacionados à medicação em uma Unidade de Terapia Intensiva. Métodos: Estudo transversal que incluiu 116 registros de internações hospitalares no período de 12 meses. 0 instrumento de pesquisa foi elaborado com base nas variáveis de estudo e validado por dois experts. A prevalência foi calculada considerando o número de internações expostas como numerador e o total de internações investigadas como denominador, calculando intervalo de confiança de 95\%. Para a verificação de associação significativa entre as variáveis, utilizou-se o Teste Exato de Fisher, assumindo nível de significância máximo de $5 \%(p<0,05)$.

Resultados: Verificou-se que 113 internações foram expostas a pelo menos um tipo de incidente, totalizando 2.869 ocorrências, sendo 1.437 circunstâncias notificáveis, 1.418 incidentes sem dano, nove potenciais eventos adversos e cinco eventos adversos. Os incidentes aconteceram durante a fase da prescrição $(45,4 \%)$ e a ausência de conduta dos profissionais de saúde frente aos incidentes foi identificada em $99 \%$ dos registros. Conclusão: Estimou-se prevalência de 97,4\% incidentes relacionados à medicação.

¿Universidade de Brasília, Brasília, DF, Brazil.

¿Universidade Federal de Goiás, Goiânia, GO, Brazil.

3Faculdade Estácio de Sá de Goiás, Goiânia, G0, Brazil.

Conflicts of Interest: there are no conflicts of interest to declare. 


\section{Introduction}

Drug therapy is widely used in intensive care units. It is used twice as much as in other hospital units because of the nature of the care provided and critical patient profiles requiring complex, urgent interventions. $^{(1)}$

Incorrect use and absence of safety standards undermine the efficacy of drugs and may cause serious incidents for patients and health institutions. ${ }^{(2)}$

Medication-related incidents are circumstances or events that may or may not cause unnecessary harm to the patient. They are classified as: reportable circumstances, no-harm incidents, near-miss incidents and adverse events. ${ }^{(3,4)}$

According to international studies, such incidents may affect up to 947 of 1,000 patients per day in intensive care units, increasing hospital costs up to $\$ 2.8$ million. ${ }^{(5,6)}$

In 2009 in Brazil, 305 medication-related incidents were identified in 44 patients hospitalized in an intensive care unit evaluated over a period of 30 days. $^{(7)}$

In this sense, intensive care units are identified as high-risk scenarios for medication-related incidents, whether due to the instability of the clinical condition of the patients or to the variability of situations and time pressure to which health care professionals are subjected, particularly nursing staff. ${ }^{(1)}$

Despite advances in studies about medication-related incidents, it remains difficult to measure their extent, characteristics and prevalence, hindering coping with and management of risks related to drug therapy in intensive care units. ${ }^{(7)}$

Thus, this study aimed to estimate the prevalence of medication-related incidents identified in records of patients hospitalized in an intensive care unit in a teaching hospital.

\section{Methods}

Cross-sectional study conducted in the intensive care unit of a tertiary school hospital located in the city of Goiânia, central region of Brazil. The insti- tution is part of the Unified Health System of the Brazilian government and has had a risk management service since 2002 that encourages reporting of incidents.

The population of the study consisted of 116 records of patients hospitalized in the intensive care unit in the period from January 1 to December 31, 2011. All patients who were admitted to the unit within the period of the study and had made use of drugs during the hospitalization period were considered. The research tool was structured and pre-validated by two experts in patient safety, and included the following variables: gender, age, duration of hospitalization, hospital specialty, clinical outcome, number of medications in use, number of doses used, clinical outcome, type of incident, type of problem, stage of the process, shift in which the incident occurred and behavior of the professional in relation to the incident.

The Conceptual Framework for the International Classification for Patient Safety proposed by the World Health Organization was adopted to classify the variable "type of incident." According to this classification, a reportable circumstance is a situation in which there is significant potential for harm but no incident occurs; a no-harm incident is an event that reaches the patient but no harm occurs; a near miss is an incident that is intercepted before reaching the patient; and an adverse event is an incident that results in harm to the patient. ${ }^{(3,4)}$

Data were descriptively analyzed with the Statistical Package for Social Science, version 22.0 for Windows, presenting absolute and relative frequencies. The prevalence was calculated by considering the number of exposed hospitalizations as the numerator and the total of investigated hospitalizations as the denominator, calculating a 95\% confidence interval. Fisher's exact test assuming a maximum significance level of $5 \%(p<0.05)$ was used to verify significant association.

The development of the study complied with national and international standards of ethics in research involving human beings. 


\section{Results}

All 116 hospitalizations that occurred in 2011 were analyzed. A predominance of female patients (52.6\%) was observed, and the average age was 56.3 years. Infectious diseases accounted for $21.5 \%$ of the admissions in the unit. The mean hospitalization period was 10.5 days and the death rate was $84 \%$. The use of drugs in the unit produced 1,272 prescription sheets, totaling 30,257 doses prescribed during the period of analysis.

The study identified 2,869 incidents in 113 hospitalizations, an estimated prevalence of $97.4 \%$ (IC 95\%; 93.1 - 99.3\%). Reportable circumstances were the most prevalent type of incident, at $88.7 \%$ (IC 95\%; 82.0 - 93.6\%), followed by no-harm incidents at 87\% (IC 95\%; $80-92.2 \%$ ), near-misses at $6 \%$ (IC 95\%; $2.6-11.5 \%$ ) and adverse events at $2.5 \%$ (IC 95\%; $0.6-6.8 \%$ ).

There were 1,437 cases of reportable circumstances registered during the hospitalizations. Higher occurrence was observed during the prescription and record stages, as shown in table 1 . Absence of administered drug checks was the type of reportable circumstance that presented higher incidence (47.9\%), followed by absence of annotations about administration of drugs (21.1\%). The study also demonstrated the practice of early prescription (7.7\%), which involves inserting a drug into a prescription sheet on a different day of its administration, thus increasing the risk of inadvertent administration.

Table 2 describes the 1,418 no-harm incidents detected; most were related to the drug prescription and administration stages. It emphasizes the occurrence of incomplete prescriptions in $62.4 \%$ of the cases and omission due to lack of drugs in the health care institution in $22.3 \%$, indicating lack of planning and/or resources to fully assist patients.

In relation to the records of near-miss and adverse events, 14 records were found, as described in Table 3. Regarding near-miss incidents, it is emphasized that interception of extra doses due to incorrect scheduling was the most recurrent incident (88.9\%). In relation to adverse events, it was
Table 1. Reportable circumstances

\begin{tabular}{lc}
\hline Type of problem & $\mathrm{n}(\%)$ \\
\hline Absence of administered drug check & $689(47.9)$ \\
Absence of annotation about drug administration & $303(21.1)$ \\
Prescription with time duplication & $256(17.8)$ \\
Early prescription & $111(7.7)$ \\
Verbal drug suspension & $40(2.8)$ \\
Lack of equipment to administer drugs (masks, expanders and others) & $24(1.7)$ \\
Prescription with impaired print & $11(0.8)$ \\
Prescription with drug duplication & $2(0.1)$ \\
Prescription in improper form & $1(0.1)$ \\
Total & $1,437(100)$ \\
\hline
\end{tabular}

Table 2. No harm incidents

\begin{tabular}{lc}
\hline Type of problem & n(\%) \\
\hline Incomplete prescription (missing dose, route, interval and/or other information) & $883(62.4)$ \\
Omission by lack of drug in the institution & $316(22.3)$ \\
Failure in dose scheduling and intervals & $121(8.4)$ \\
Prescription of non-standard drugs & $30(2.1)$ \\
Lapses, misconceptions and/or failures in dispensation & $21(1.5)$ \\
Omission by patient out of the unit & $9(0.6)$ \\
Unauthorized administration: Suspension of drug without notifying the nursing staff & $9(0.7)$ \\
Extra dose due to early prescription & $7(0.5)$ \\
Illegible drug name & $5(0.4)$ \\
Omission resulting from lack of device to administer the drug & $5(0.4)$ \\
Delay in administration schedule & $5(0.4)$ \\
Anticipation in administration schedule & $3(0.2)$ \\
Prescription to patient that is known to be allergic & $2(0.1)$ \\
Pharmacy refused to accept the request & $1(0)$ \\
Extra dose due to duplicate prescription & $1(0)$ \\
Total & $1,418(100)$ \\
\hline
\end{tabular}

observed that $100 \%$ were avoidable and occurred during the administration stage.

Regarding the time of occurrence of the incidents, it was verified that $69 \%$ occurred during the daytime. It was also found that only in $1 \%$ of occurrences did health care professionals report the therapeutic decision shortly after identification of the incident. These include: suspension of drug administration $(0.6 \%)$, adjustment of the activity $(0.3 \%)$ and additional monitoring $(0.1 \%)$.

The results obtained in the Fisher's exact test showed that the occurrence of reportable circumstance was significantly associated with males $(\mathrm{p}=0.021)$, hospitalization time of up to 5 days $(p=0.000)$ and use of up to 20.9 doses per day $(\mathrm{p}=0.015)$. No-harm and near-miss incidents presented associations with length of hospitalization of up to 5 days $(p=0.003)$. No significant association between the variables was verified for adverse events. 
Table 3. Near-miss and adverse events

\begin{tabular}{lc}
\hline Variables & $\mathrm{n}(\%)$ \\
\hline Near-miss incidents & \\
Prescription to patient that is known to be allergic & $1(11.1)$ \\
Additional dose due to incorrect scheduling & $8(88.9)$ \\
Total & $9(100)$ \\
Adverse events & \\
Hypertension by dose omission & $2(40)$ \\
Adverse reaction to drug & $3(60)$ \\
Total & $5(100)$ \\
\hline
\end{tabular}

\section{Discussion}

The present study has limitations in relation to the method that should be considered in the interpretation of the results. As such situations could result in penalties, the possibility of omission of some records of incidents and their consequences to professionals is considered. In addition, the review of retrospective data in secondary sources must also be considered in view of the quality of hospital records in Brazil.

However, the study provides deeper insight into the problem of medication-related incidents in intensive care units, contributing to review of work processes and supporting the development and implementation of preventive actions targeting the quality and safety of patient assistance.

The first finding of this study was that the death rate in the investigated scenario was extremely high, surpassing findings of an international multicenter survey. ${ }^{(8)}$ The high death rate was related to the patient profiles, which were severe, with several comorbidities and multiple concurrent clinical problems. ${ }^{(9)}$ Combined with this, Brazil presents constant unavailability of beds in intensive care units, which hinders access by patients and affects the survival rate and therapeutic possibilities. ${ }^{(10)}$

The findings on reportable circumstances in this study provide knowledge about another dimension of medication-related incidents in intensive care units, in which the events are inserted into the everyday context of the structure and work processes of the unit. In this sense, several publications presented satisfactory results in patient safety resulting from redesign of work processes and involvement of healthcare professionals. ${ }^{(11,12)}$
It was observed that medication-related incidents were common in intensive care units. And although a very small fraction caused harm to patients, it is still necessary to manage the risks related to the medication process, considering that critical patients present higher needs for care and are therefore more vulnerable. ${ }^{(13)}$

It was also found that near-miss incidents showed low prevalence. However, at the same that they demonstrate failures in carrying out activities, they also show the human capacity to intercept incidents. Most of the near-miss incidents were related to the administration stage, especially involving the interception of additional doses and the prescription of drugs to patients known to be allergic.

The results contribute to the capacity of nursing teams to intercept medication-related incidents, which constitute a major barrier to patient safety. $(14,15)$ However, the low number of records of nearmiss incidents suggests the need to encourage and improve this capacity in light of the constitution of this defense barrier to patient safety in intensive care units. As nursing team professionals essentially work in the final stage of drug therapy, their responsibility for identifying and preventing such failures increases, as the administration act may interrupt the system and prevent mistakes initiated in early stages.

Adverse events presented a prevalence of $2.5 \%$, and all the cases were related to the administration stage; most were generated by dose omission and adverse reactions to medications. These results significantly diverged from other national and international research. ${ }^{(5,16)}$ This difference suggests underreporting that masks the true magnitude of the events and undermines the quality of the care provided, also revealing a possible aspect of the organizational culture of institutions, as only $1 \%$ of the records described the actions of professionals in cases of incidents.

In many cases, reporting is seen as a rendering of accounts, which is also a barrier to voluntary reporting. ${ }^{(17)}$ Understanding safety in the medication process in a punitive way contributes neither to the development of assertive care practices nor to the 
development of institutional safety culture in organizations.

Safety culture expresses individual and collective values, attitudes, skills and behavior patterns that determine the commitment and proficiency of safety and health programs in organizations. When organizations can build positive safety culture, they attain better levels of communication, common perceptions of the importance of safety, and confidence in the effectiveness of preventive actions. ${ }^{(18)}$

The prescription stage had a higher proportion of incidents, similar to results found in other international research. Incidents in this stage of the medication process are common and must be confronted by professionals and health managers, especially in teaching hospitals, where safety culture - if implemented during the formation of health professionals - may result in changes in the health system. ${ }^{(6)}$

Daytime was the period that presented a higher number of occurrences, similar to findings by national studies in intensive care units. This is related to the proportionally higher volume of drugs administered during this period. ${ }^{(6,7)}$

It was observed that occurrences of medication-related incidents were associated with periods of hospitalization above 5 days, male patients and daily use of multiple doses of drugs. There is a consensus in several studies that prolonged hospital stays increase the exposure of patients to risks of being affected by incidents or failures during the care process and to the several environmental and intrinsic factors of a hospital environment. ${ }^{(19,20)}$

The administration of large amounts of drugs per day may confuse health professionals and lead to incidents, as observed in an international study. ${ }^{(21)}$ However, the findings of that study suggested that other variables should also be considered, given that the prevalence of incidents was inversely proportional to the number of doses per day. These considerations reinforce the fact that the success of drug therapy in intensive care units involves conscious multidisciplinary work, appropriate staff assignments and a systemic approach to failures. ${ }^{(22)}$

\section{Conclusion}

The study identified 2,869 medication-related incidents, with prevalence of $97.4 \%$ of exposed hospitalizations. Of these, $45.5 \%$ was related to the prescription stage and $99 \%$ of the records did not present the actions of the health professionals in relation to the incidents.

\section{Collaborations}

Azevedo Filho FM and Pinho DLM declare that they contributed in the stages of conception and project, data analysis and interpretation, elaboration of the article, critical review pertinent to intellectual content and final approval of the version to be published. Bezerra ALQ; Amaral RT and Silva ME collaborated in the elaboration of the article, critical review pertinent to intellectual content and final approval of the version to be published.

\section{References}

1. Camire E, Moyen E, Stelfox HT. Medication errors in critical care: risk factors, prevention and disclosure. Can Med Assoc J. 2009;180(9):93643.

2. Manias E, Williams A, Liew D. Interventions to reduce medication errors in adult intensive care: a systematic review. Br J Clin Pharmacol. 2012;74(3):411-23.

3. Runciman W, Hibbert P, Thomson R, Van Der Schaaf T, Sherman H, Lewalle P. Towards an International Classification for Patient Safety: key concepts and terms. Int J Qual Health Care. 2009;21(1):18-26.

4. Sherman H, Castro G, Fletcher M, Hatlie M, Hibbert P, Jakob R, et al. Towards an International Classification for Patient Safety: the conceptual framework. Int J Qual Health Care. 2009;21(1):2-8.

5. Kane-Gill S, Weber RJ. Principles and practices of medication safety in the ICU. Critical Care Clin. 2006;22(2):273-90.

6. Latif A, Rawat N, Pustavoitau A, Pronovost PJ, Pham JC. National Study on the distribution, causes, and consequences of voluntarily reported medication errors between the ICU and non-ICU settings. Crit Care Med. 2013;41(2):389-98.

7. Bohomol E, Ramos LH, D'Innocenzo M. Medication errors in an intensive care unit. J Adv Nurs. 2009;65(6):1259-67.

8. Gabler NB, Ratcliffe SJ, Wagner J, Asch DA, Rubenfeld GD, Angus DC, et al. Mortality among patients admitted to strained intensive care units. Am J Respr Crit Care Med. 2013;188(7):800-06.

9. Garrouste-Orgeas M, Philippart F, Bruel C, Max A, Lau N, Misset B. Overview of medical errors and adverse events. Ann Intensive Care. 2012;2(1):2.

10. Cardoso LT, Grion CM, Bonametti AM, Seko LM, Zampa HB, Ferreira GL. Intensive care unit bed shortage leading to a delay in patient admission 
to public intensive care units. Crit Care. 2007;11(Suppl 3):1-2

11. Alper SJ, Holden RJ, Scanlon MC, Patel N, Kaushal R, Skibinski K, et al. Self-reported violations during medication administration in two paediatric hospitals. BMJ Qual Saf. 2012;21(5):408-15.

12. Donihi AC, DiNardo MM, DeVita MA, Korytkowski MT. Use of a standardized protocol to decrease medication errors and adverse events related to sliding scale insulin. Qual Saf Health Care. 2006;15(2):8991.

13. Rothschild JM, Landrigan CP, Cronin JW, Kaushal R, Lockley SW, Burdick E, et al. The Critical Care Safety Study: The incidence and nature of adverse events and serious medical errors in intensive care. Crit Care Med. 2005;33(8):1694-700.

14. Costello JL, Torowicz DL, Yeh TS. Effects of a pharmacist-led pediatrics medication safety team on medication-error reporting. Am J Health Syst Pharm. 2007;64(13):1422-6.

15. Kazemi A, Fors UG, Tofighi S, Tessma M, Ellenius J. Physician order entry or nurse order entry? Comparison of two implementation strategies for a computerized order entry system aimed at reducing dosing medication errors. J Med Internet Res. 2010;12(1):e5.

16. Kane-Gill SL, Jacobi J, Rothschild JM. Adverse drug events in intensive care units: risk factors, impact, and the role of team care. Crit Care
Med. 2010;38(Suppl 6):S83-9.

17. Braithwaite J, Westbrook M, Travaglia J. Attitudes toward the largescale implementation of an incident reporting system. Int J Qual Health Care. 2008;20(3):184-91.

18. Halligan $M$, Zecevic A. Safety culture in healthcare: a review of concepts, dimensions, measures and progress. BMJ Qual Saf. 2011;20(4):33843.

19. Breeding J, Welch S, Whittam S, Buscher H, Burrows F, Frost C, et al. Medication Error Minimization Scheme (MEMS) in an adult tertiary intensive care unit (ICU) 2009-2011. Aust Critical Care. 2013;26(2):5875.

20. Dickinson CJ, Wagner DS, Shaw BE, Owens TA, Pasko D, Niedner MF. A systematic approach to improving medication safety in a pediatric intensive care unit. Crit Care Nurs Q. 2012;35(1):15-26.

21. Kane-Gill SL, Kirisci L, Verrico MM, Rothschild JM. Analysis of risk factors for adverse drug events in critically ill patients. Crit Care Med. 2012;40(3):823-8.

22. Azevedo Filho F, Soares Martins IM, Rodrigues Silva Soares CS, Gomes Fazendeiro P, Tanferri de Brito Paranaguá T, Queiroz Bezerra AL. Administración de medicamentos: conocimiento de los enfermeros del sector de urgencia y emergencia. Enfermería Global. 2012;11:54-69. 